\title{
Design and development of a kinetic energy harvester device for oceanic drifter applications
}

\author{
Matias Carandell \\ Sarti Research Group. Electronics \\ Engineering Department. \\ Universitat Politècnica de Catalunya \\ Vilanova i la Geltrú, Spain \\ matias.carandell@upc.edu \\ Manel Gasulla \\ e-CAT Group. Electronics Engineering \\ Department. \\ Universitat Politècnica de Catalunya \\ Castelldefels, Spain \\ manel.gasulla@upc.edu
}

\author{
Daniel Mihai Toma \\ Sarti Research Group. Electronics \\ Engineering Department. \\ Universitat Politècnica de Catalunya \\ Vilanova i la Geltrú, Spain \\ daniel.mihai.toma@upc.edu \\ Joaquín del Río \\ Sarti Research Group. Electronics \\ Engineering Department. \\ Universitat Politècnica de Catalunya \\ Vilanova i la Geltrú, Spain \\ joaquin.del.rio@upc.edu
}

\author{
Montserrat Carbonell \\ Sarti Research Group. Electronics \\ Engineering Department. \\ Universitat Politècnica de Catalunya \\ Vilanova i la Geltrú, Spain \\ montse.carbonell@upc.edu
}

\begin{abstract}
A novel electronic energy harvester (EH) has been developed for oceanic undrogued drifter applications. First, spherical body motion simulation has been performed at sea environment in Orcaflex. Results help to understand the acceleration and forces applied on the drifter where the device will be placed. Second, the design of the EH is presented, consisting on a gyroscope pendulum system capable to transform the oscillations into rotation on a flying wheel. This rotation is converted into a $\mathrm{DC}$ current by a micro generator and further processed by a power management unit (PMU). Both, the generator and the PMU are characterized. Preliminary results in a water tank show that an average power of $0.22 \mathrm{~mW}$ can be produced. Finally, the feasibility of the proposed harvester is assessed as a backup power of a drifter using SigFox for coastal communications at low tracking rates.
\end{abstract}

Keywords- Lagrangian Drifter, Energy Harvester (EH), Autonomous Sensor, Power Management Unit (PMU), Maximum Power Point Tracking (MPPT), low-power wide-area network (LPWAN), SigFox

\section{INTRODUCTION}

Science community needs related to oceanographic data are growing fast. Seas should be monitored in order to preserve their biodiversity and predict their evolution. This means that huge amounts of data from a very wide range of sensors should be generated and delivered as fast as possible. Research vessels collecting data from the ocean during long periods are becoming unusual due to their high-cost [1]. As a consequence, cabled observatories, gliders, pop-up drifters and long-term moorings are taking their place and are delivering enormous amounts of real or near-real time data to this community. One of these sea data providers are Lagrangian Drifters. These are autonomous floating passive devices that provide oceanographic surface data such as oceanic current flow, temperature, or salinity. They are used in climate research, oil spill tracking, or search and rescue operations. The National Oceanic and Atmospheric Administration counts on a drifter array of more than 1300

This work was supported by the project MELOA from the European Commission's Horizon 2020 research and Innovation program under Grant Agreement No. 776280 and by the Spanish Ministry of Economy and Competitiveness and the European Regional Development Fund under project TEC2016-76991-P. The first author has a grant from the Secretariat of Universities and Research of the Ministry of Business and Knowledge of the Government of Catalonia on the FI program (ref. BDNS 362582). units deployed around the world and their data can be online accessed for scientific community in [2].

Many commercial drifters can be found in the market, from drogued to undrogued, depending on the ocean depths to be monitored. Basic drifters offer ocean current tracking and near surface temperature but they are evolving and now some of them can be found with Acoustic Doppler Current Profilers, salinity sensors, or weather stations. On the other hand, wireless communication is performed via GSM nearshore or via satellite (mostly Iridium-based) off-shore. Most of them also offer the possibility of bidirectional communication to modify parameters of the buoy [3]-[9].

Lumpkin et al. [10] describe the challenges related to the evolution and applications of drifters: measurement of currents, near-surface temperature and salinity or ocean dispersion, among others. Autonomy is one of the key points at drifters. Depending on the carried instruments and the duty cycle of the units, its lifespan may vary from hours up to two years when powered from primary batteries. If unlimited lifespan is pretended, some companies present drifters with PV solar panels that at some sampling interval may work at "perpetual" lifespan. The installed PV power is around units of watts [11]-[14].

Drifters strictly dedicated to monitor superficial ocean current should not be exposed to wind. Consequently, they must be mostly submerged with the exception of the communication antenna, which has to be out of the water. Even so, as demonstrated in [15], the downwind "slippage" at undrogued drifters is around $1 \%$ of the wind speed. This problem can be magnified when using PV panels that are out of water to ensure direct irradiation, as in [13]. On the other hand, when PV panels are inside the drifter sunlight is greatly attenuated by the water, as in [11].

In this work, as an alternative, a kinetic energy harvester (EH) system is presented, which uses the motion of the waves and the current flow to generate power. The $\mathrm{EH}$ is inside the drifter and thus does not increases the wind slippage of the unit. However, the generated power is relatively low and cannot provide the main power supply yet. The aim at this stage is to serve as an unlimited backup powering system, when the primary batteries are exhausted, allowing the drifter to send messages about its location in order to recover it. 
The paper is organized as follows. First, the simulation of a drifter motion in a fluid is presented at section II. Then, the proposed kinetic EH device is shown in section III. At section IV, the micro generator and the power management unit (PMU) are characterized while preliminary results show up at section V. Finally, the feasibility of the present system for drifter applications is discussed at section VI and section VII concludes the work.

\section{Motion SIMULATION}

\section{A. Model}

A spherical object of radius $R$ (the drifter) mostly submerged into the water will be exposed to water-structure interaction. Fig. 1 shows a representation, where $z$ is the vertical axis (positive upwards) and $w$ is the position of the water line of the waves with respect to the still case. Therefore, understanding the dynamic motion response of a drifter due to external wave loading is essential in order to properly design kinetic EH devices.

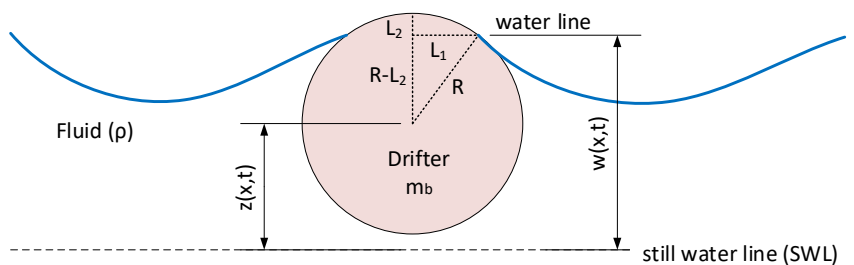

Fig. 1. Model of a mostly submerged drifter subjected to wave loading.

A study is performed in [16] and is concluded that a particle placed in a fluid with sufficiently deep water will follow the water line in a circular motion, as can be seen at Fig. 2. That motion will depend on the body characteristics, such as buoyancy and center of mass, and sea wave parameters such as the height and period.

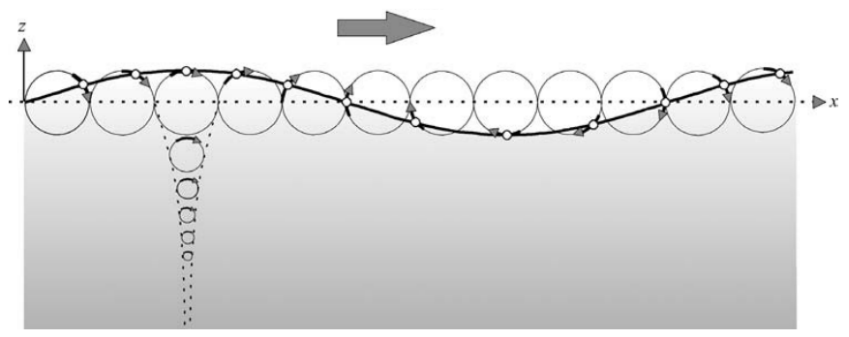

Fig. 2. Particle surface movement under wave interaction [16].

\section{B. Numerical simulations}

OrcaFlex 9.3c, a marine dynamics software implemented by Orcina based on Morison's equations [17], was used to study the dynamics of the spherical body into the water Simulations were performed with a spherical body such as that of Fig. 1 with the parameter values of TABLE I, coming from a planned undrogued drifter. Sea wave parameters were set between 1 to 6 meters for height and 4 to 12 seconds for period, which according to [18] are the most probable ocean conditions for North Atlantic Ocean. The ocean waves have been simulated in OrcaFlex using the JONSWAP spectrum, which is suitable for simulating deep-water waves.

TABLE I. Spherical drifter parameters on OrcaFlex simulation

\begin{tabular}{|c|c|c|c|}
\hline Parameter & Symbol & Value & Units \\
\hline Drifter mass & $m_{\mathrm{b}}$ & 3.472 & $\mathrm{~kg}$ \\
\hline
\end{tabular}

\begin{tabular}{|l|c|c|c|}
\hline \multicolumn{1}{|c|}{ Parameter } & Symbol & Value & Units \\
\hline Drifter radius & $R$ & 0.1 & $\mathrm{~m}$ \\
\hline Fluid density & $\rho$ & 1027 & $\mathrm{~kg} / \mathrm{m}^{3}$ \\
\hline Center of mass $^{\mathrm{a}}$ & $c_{\mathrm{m}}$ & 0.08 & $\mathrm{~m}$ \\
\hline \multicolumn{4}{|c|}{${ }^{\text {a. }}$ Center of mass taken from the bottom of the spherical drifter body. }
\end{tabular}

\section{Results}

Results of the simulation are summarized in Fig. 3, where drifter vertical ( $\mathrm{z}$ direction) and pitch accelerations are plotted. Values represent the average of the absolute instantaneous acceleration during a 100 seconds simulation. The unusual wave conditions have not been simulated. So, waves of high heights and low periods and of low heights and high periods have not been considered. Vertical body acceleration is between 0.1 to $2 \mathrm{~m} / \mathrm{s}^{2}$ and pitch acceleration is between 0.1 to $15 \mathrm{rad} / \mathrm{s}^{2}$. Maximum accelerations, which should lead to a higher mechanical power of the EH presented in section III, occur at higher heights and lower periods (higher frequencies). In [16], the mechanical power at the axis of a gyroscope is modelled and found to also increase with the wave height and frequency.
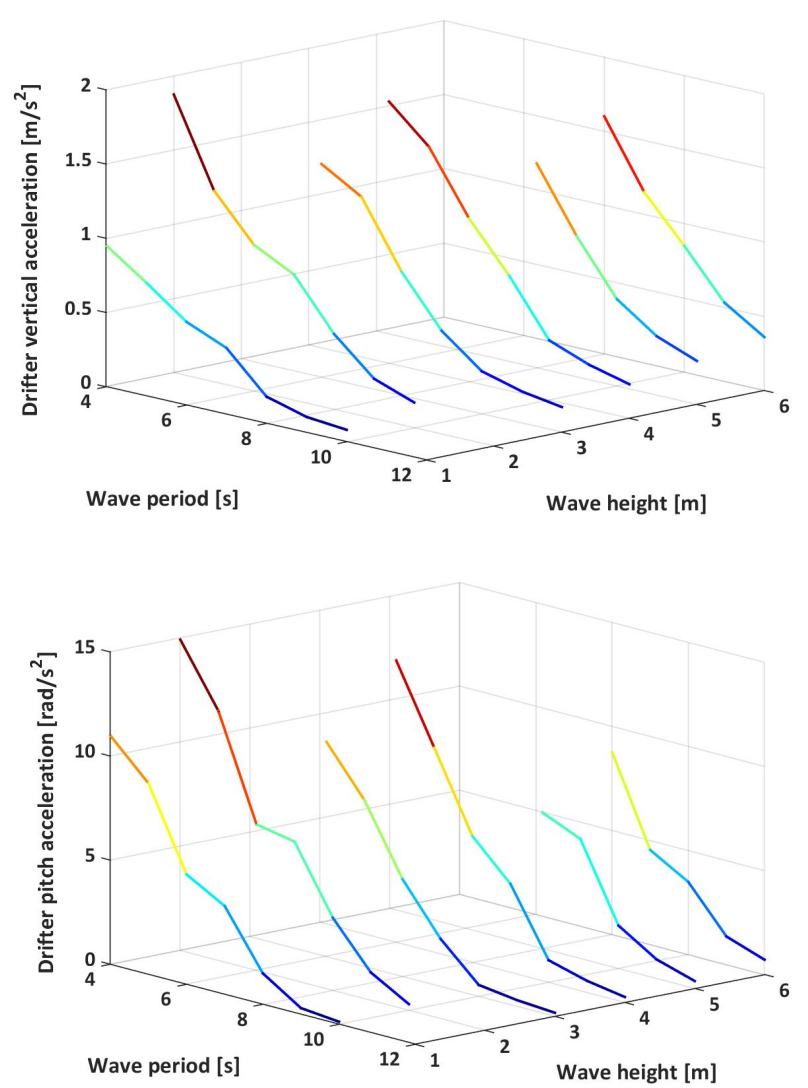

Fig. 3. Drifter vertical (above) and pitch (below) accelerations at different wave heights and periods.

\section{Proposed KINETIC ENERGY HARVESTER DEVICE}

Many works propose EH devices that use kinetic energy from an anarchic source at relative low frequencies and high amplitudes (like sea motion). For example, for biomedical applications, walking body motion is used to generate power using an electromagnetic transducer. In [19], a sprung eccentric rotor is used in order to induce an electrical current. Higher energy levels are achieved using a pendulum and a dc micro generator at [20] and converting the bidirectional rotating movement into unidirectional through a gear system. 
At sea environment, recent works show that the most usual approach to generate electrical energy is turning oscillations into rotations and using a generator as a transducer. Work done at [21] shows an ac generator based harvester placed on an underwater glider. It reaches $150 \mathrm{~mW}$ of mean output power with a volume around $0.1 \mathrm{~m}^{3}$ and waves of $100 \mathrm{~cm}$ height and $1.3 \mathrm{~s}$ period. At [22], they use a dc generator that reaches $64 \mathrm{~mW}$ of maximum output power with a $500 \mathrm{~cm}^{3}$ volume device and waves of $20 \mathrm{~cm}$ height and $1 \mathrm{~s}$ period. In [23], a design similar to our design (presented below) is reported, as it uses a gyroscope with a flying wheel, reaching a mean output power level of watts with a $0.5 \mathrm{~m}^{3}$ volume (much larger than ours). However, it is an anchored buoy.

A general schematic of the designed kinetic EH device is shown in Fig. 4. The design is comprised of a gymbal system, a gearing transmission to transform the oscillations to rotation, a proof mass, a flywheel, and a micro electromagnetic generator. As a result of the interaction with the waves, the drifter, which contains the EH (Fig. 5), rotates with a pitching, roll and yaw motion. Then, the proof mass, which tries to maintain the vertical position by the gravity effect, rotates in relation with the drifter thanks to the gymbal arms. That generates a torque along the axis that through the gear system gets to the flywheel. There, the rotational movement is accumulated and then transmitted to the micro generator responsible for converting the torque into electrical power. Thanks to the one-way gear system, the generator only turns in one direction.

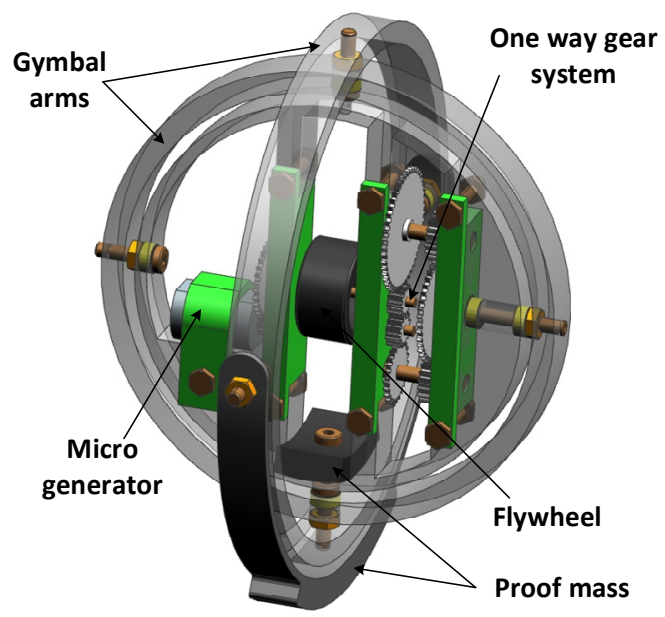

Fig. 4. Architecture of the proposed EH.

A first prototype of the $\mathrm{EH}$ has been manufactured with a mass of $360 \mathrm{~g}$ and a diameter of $12 \mathrm{~cm}$. A picture of this prototype is shown at Fig. 6. Gimbal arms are made of methacrylate and the green supports are manufactured in a $3 \mathrm{D}$ printer with ABS plastic. The gear ratio is of 35 and the micro generator is a miniature DC motor with a nominal voltage of $3 \mathrm{~V}$ used in a reverse mode, i.e. using the electrical input as the output. An sketch is shown at Fig. 5 of the EH placed inside an undrogued drifter with the corresponding battery pack, the electronics and the antenna.

\section{POWER GENERATION AND TRANSFER}

\section{A. Generator and PMU description}

In self-powered autonomous systems, energy management is crucial in order to maximize the lifespan of the device and to guarantee the most efficient way to handle the generated energy. Here, energy provided by the micro generator of the EH has to be managed. To achieve this, a PMU with a maximum power point tracker (MPPT) is required. Toh et al. designed in [24] a system to follow the maximum power point (MPP) of a micro generator by controlling the duty cycle of a boost converter who gives the power to a dc-link and a flyback converter to adequate the voltage level at the load. From then, many conversion systems have been developed depending on the energy source and [25] presents a summary. These ultralow PMU follow the MPP of the energy transducer and transfer the energy to a storage device, which tend to be a Li-ion battery, a super capacitor, or a hybrid storage system [26].

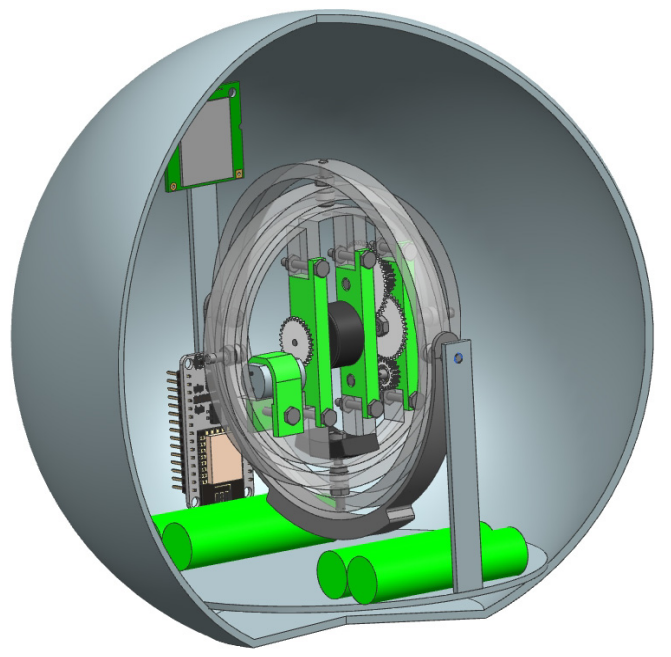

Fig. 5. Sketch of the kinetic EH placed inside an undrogued drifter, with battery pack, antenna and electronics.

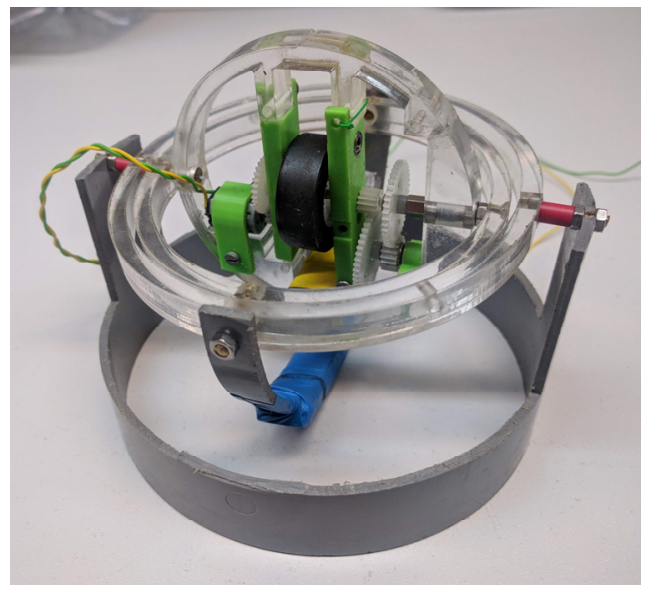

Fig. 6. Picture of the prototype of the designed kinetic EH.

Recently, many commercial PMU are showing up. In this work, the evaluation board of the ADP5092 (Analog Devices) has been used. This PMU is based on a boost regulator working on PFM mode [27], which fixes the input voltage $\left(\mathrm{V}_{\mathrm{IN}}\right)$ as a fraction of the open circuit voltage $\left(V_{\mathrm{oc}}\right)$ of the EH in order to work at the MPP. It is able to control the charge with a very low internal consumption and work with $\mathrm{V}_{\mathrm{IN}}$ as low as $80 \mathrm{mV}$. On the other hand, it provides a main output (SYS terminal), a battery charging terminal (BAT) with a programmable overcharge voltage from 2.2 to $5.2 \mathrm{~V}$, and a regulated output settable from 1.5 to $3.6 \mathrm{~V}$. The micro generator can be modelled as a Thévenin equivalent, 
consisting of a voltage source $\left(V_{\mathrm{oc}}\right)$ in series with a resistor $R_{\mathrm{G}}$. Maximum power will be harvested when loaded with a load $\left(R_{\mathrm{LOAD}}\right)$ equal to $R_{\mathrm{G}}$. At this condition, $\mathrm{V}_{\mathrm{IN}}$ will be half $V_{\text {oc. }}$ Fig. 7 shows the connection of the micro generator, modelled as an equivalent Thévenin, to the ADP5092 PMU evaluation board.

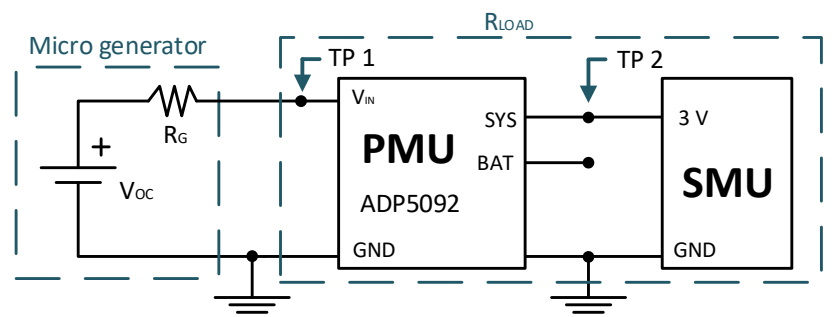

Fig. 7. Schematic of the generator and PMU.

\section{B. Preliminary characterization of the generator and PMU}

First, the micro generator was characterized. The shaft of the generator was rotated with the shaft of another DC motor at different rotation speeds, which aims to emulate those obtained from the designed device of Fig. 4, and the generator output was connected to a source measurement unit (SMU, Agilent B2901), in order to emulate different electrical loads. For each rotation speed, a voltage sweep was performed with the SMU while measuring the output power. Fig. 8 shows the experimental results, where the rotation speed in rpm is defined with no load connected to the generator output (output voltage is $V_{\text {oc }}$ ). As can be seen, for the three curves, the MPP happens around half $V_{\text {oc }}$, which is coherent with the Thévenin model of the generator [28]. In addition, $V_{\mathrm{oc}}$ is directly proportional to the rotation speed whereas the maximum power is proportional to its square. From the corresponding voltage-current characteristic (not shown), a load of around $18.5 \Omega\left(R_{\mathrm{LOAD}}\right)$ is inferred, which should match with the internal generator load $\left(R_{\mathrm{G}}\right)$. For the micro generator characterization, the uncertainty was determined at the MPP of the green curve (1530 rpm at OC). At this point, the standard deviation was $400 \mu \mathrm{W}$ given by the uncertainty of the generator output calculated from 12 measurements.

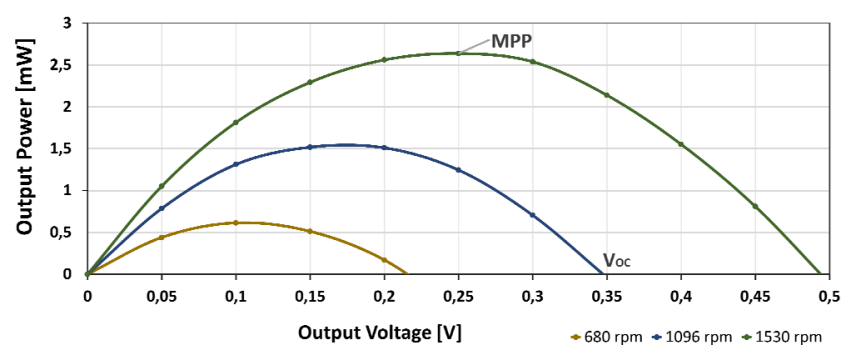

Fig. 8. Generator output power against output voltage for different shaft velocities (determined at generator open circuit).

Then, another test was performed to characterize the PMU efficiency, using the setup of Fig. 7 with the generator rotated as before. The ADP5092 was configured with $V_{\mathrm{IN}}$ at half $V_{\text {oc}}$, the regulated output disabled, and the BAT terminal floating (a capacitor of $100 \mu \mathrm{F}$ is present in the evaluation board). Its SYS output was set at $3 \mathrm{~V}$ with the SMU. Two test point were defined for measuring the input and output power (TP1 and TP2, respectively). Input power was inferred using a multimeter for measuring the average current and an oscilloscope for measuring the average voltage (fixed by the PMU at half $V_{\text {oc }}$ ). Output power was directly measured by the SMU. Fig. 9 shows the measured powers and the PMU efficiency in function of the rotation speed of the micro generator. As can be seen, all increase as the shaft speed grows. At low rotation speed, the efficiency of the ADP5092 is low because the corresponding input MPP voltage approaches the lower limit of $80 \mathrm{mV}$ but steeply increases with the rotation speed reaching almost $90 \%$.
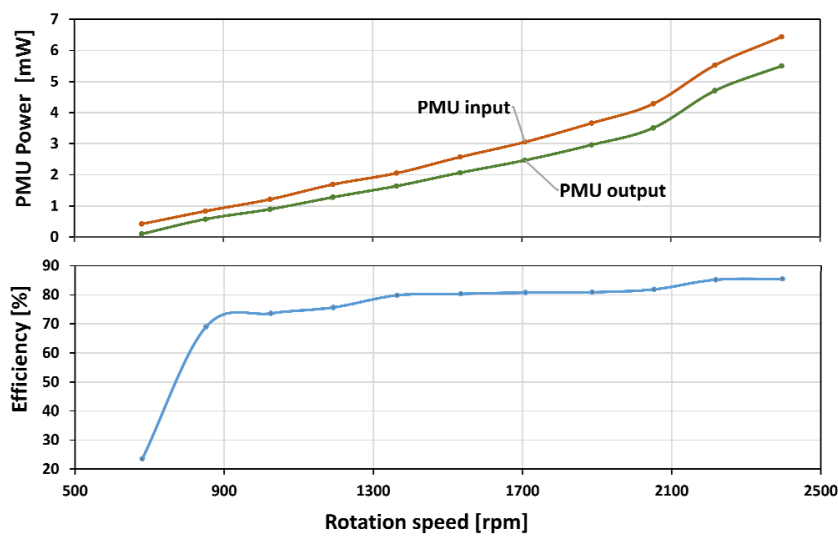

Fig. 9. PMU output power (above) and efficiency (below) in function of the rotation shaft speed.

\section{PRELIMINARY RESUlts}

The EH prototype described at section III was tested in an anchored buoy placed in a water tank simulating waves of $10 \mathrm{~cm}$ height with periods in the $3 \mathrm{~s}$ to $6 \mathrm{~s}$ range. Fig. 10 shows the output power of the EH loading the output of the generator with a $50 \Omega$ resistor (that of the oscilloscope used to measure its output voltage). The PMU was not used here. As can be seen, the output power presents a high variability, since the rotation speed is not constant, with an average value of $0.22 \mathrm{~mW}$. Maximum power is within the MPP range found at Fig. 8 .

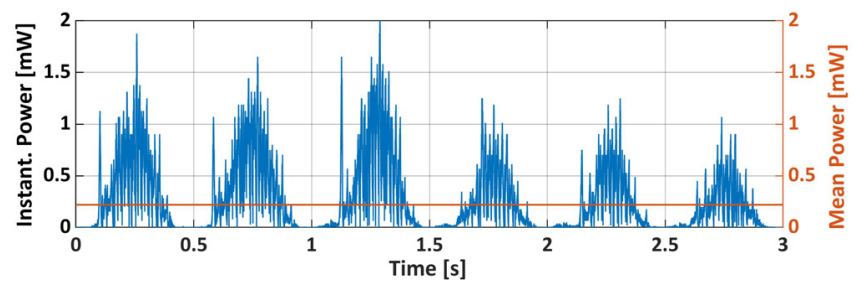

Fig. 10. Instantaneous output power of the EH device tested on the water tank with 50 Ohms load.

Then, the EH placed at the water tank was connected to the ADP5092 module to test its functionality in almost real conditions. The connection was similar to that of Fig. 7 but without the SMU. Instead, an oscilloscope was connected to $\mathrm{TP} 1(\mathrm{CH} 1)$ and TP2 $(\mathrm{CH} 2)$, and a $470 \mathrm{mF}$ super capacitor was placed at BAT terminal, at 3.6 V. Fig. 11 shows $\mathrm{V}_{\text {IN }}$ (pink - TP1) and the SYS output of the PMU (yellow). Three different regions can be appreciated, from left to right:

- First region: SYS voltage is dropping from 3.6 because the $V_{\text {IN }}$ is below the minimum working value ( $80 \mathrm{mV}$, marked with a dashed white line).

- Second region: SYS signal is $0 \mathrm{~V}$. EH is now generating power and the PMU enters in the cold startup operation.

- Third region: The EH continues generating power so SYS output terminal raise again to $3.6 \mathrm{~V}$. 


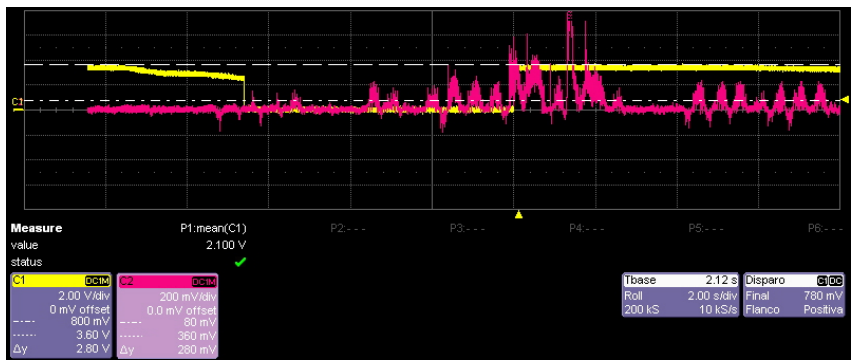

Fig. 11. Oscilloscope screenshot of system operation at water tank test.

\section{FEASIBILITY FOR DRIFTER COASTAL APPLICATION}

As said in section I, coastal (near-shore) drifters tend to be GSM communication-based. However, low-power widearea network (LPWAN) offer an attractive solution as a tracking coastal communication since they allow to send small packages at long distances with low power consumption, which is suitable for self-powered drifters as the proposed here. In particular, SigFox is a payable LPWAN technology that includes the Base Stations and the Backend Services and works at $868 \mathrm{MHz}$ (ISM band). It offers to send up to 140 messages/day per device with a payload of 12 bytes each one. Although it is a short package it is enough to send the position and some data as the temperature. The TD1205P model is a low power SigFox module that also includes the Global Navigation Satellite System (GNSS), and temperature and accelerometer sensors for tracking applications in a $30 \times 38 \times 10.5 \mathrm{~mm}$ size.

In previous works [29], the TD1205P power consumption was evaluated at transmitting and sleeping mode in a coastal area. Considering a transmitting cycle every 2 hours, the required energy per day is $18 \mathrm{~J}$. With the power generated at the water tank test (average of $0.22 \mathrm{~mW}$ ), $19 \mathrm{~J}$ can be generated per day, so the TD1205P could be fed from this EH. Moreover, with a $470 \mathrm{mF}$ super capacitor at $3.6 \mathrm{~V}$ as the one used previously, the peaks of energy at the transmitting phase $(1.3 \mathrm{~J})$ would lead to a minimum voltage of $2.73 \mathrm{~V}$, which is assumable. However, for these calculations the PMU is not considered, so further work is needed.

\section{CONCLUSIONS}

A novel EH device has been designed and developed. It counts on a gearing system that transform the pendulum oscillations into rotation in a flywheel transmitted to a micro electromagnetic generator. Furthermore, the micro generator and the ensuing ADP5092 PMU have been characterized, showing an increasing electrical power and efficiency with the rotation speed. In addition, the EH system has been tested on a water tank generating an average power of $0.22 \mathrm{~mW}$. Finally, a LPWAN technology based on SigFox is assessed as a tracking system for drifter coastal applications which can achieve 12 transmissions per day. The generated output power of $0.22 \mathrm{~mW}$ is estimated to be enough to power the SigFox module; however, the efficiency of the PMU has not already been taken into account.

\section{ACKNOWLEDGMENT}

The authors extend their thanks to Orcina for their kind support and offer of the academic license OrcaFlex N2703 (2018) to Universitat Politècnica de Catalunya. Also, the authors want to acknowledge Albert Garcia-Benadí for the uncertainty calculations of the measurements.

\section{REFERENCES}

[1] R. E. Thomson and W. J. Emery, Data Analysis Methods in Physical Oceanography: Third Edition. 2014.

[2] National Oceanic and atmospheric Administration. Atlantic Oceanographic and Meteorological Laboratory, "Global Drifter Array. NOAA." [Online]. Available: http://www.aoml.noaa.gov/phod/gdp/index.php.

[3] L. Emery, R. Smith, R. McQuary, B. Hughes, and D. Taylor, “Autonomous River Drifting Buoys,” Oceans, pp. 1-5, 2011.

[4] "Lagrangian Drifter Laboratory." [Online]. Available: http://gdp.ucsd.edu/ldl_drifter/index.html.

[5] "Pacific Gyre.” [Online]. Available: https://www.pacificgyre.com/.

[6] K. Raghukumar, G. Chang, F. Spada, C. Jones, W. Gans, and T. Janssen, "Wave-Measuring Performance Characteristics of Spoondrift Spotter," 5th Annu. Mar. Energy Technol. Symp., p. 2017, 2017.

[7] “Albatros." [Online]. Available: http://albatrosmt.com/inicio/.

[8] "Fastwave." [Online]. Available: http://www.fastwave.com.au/.

[9] "Marine Instruments." [Online]. Available: http://www.marineinstruments.es/.

[10] R. Lumpkin, T. Özgökmen, and L. Centurioni, "Advances in the Application of Surface Drifters," Ann. Rev. Mar. Sci., vol. 9, no. 1, pp. 59-81, 2017.

[11] Albatrosmt, "Ocean Drifter iridium buoy."

[12] Marine Instruments, "M3i Sounder buoy."

[13] Spoondrift, "Spoondrift Spotter.," pp. 1-2, 2017.

[14] Fastwave, "VOYAGER SOLAR DRIFTER BUOY." [Online]. Available: http://systems.fastwave.com.au/media/2102/fastwavevoyager-solar.pdf.

[15] P. M. Poulain, R. Gerin, E. Mauri, and R. Pennel, "Wind effects on drogued and undrogued drifters in the eastern Mediterranean," $J$. Atmos. Ocean. Technol., vol. 26, no. 6, pp. 1144-1156, 2009.

[16] M. Carlsen et al., "Efficiency of a gyroscopic device for conversion of mechanical wave energy to electrical energy," Technical report from ESGI-83 workshop in industrial mathematics. 2011.

[17] J. R. Morison, J. W. Johnson, and S. A. Schaaf, "The Force Exerted by Surface Waves on Piles,” J. Pet. Technol., 1950.

[18] R. Atan, J. Goggins, and S. Nash, "A Detailed Assessment of the Wave Energy Resource at the Atlantic Marine Energy Test Site," Proc. 11th Eur. Wave Tidal Energy Conf., pp. 1-8, 2016.

[19] M. A. Halim, R. Rantz, Q. Zhang, L. Gu, K. Yang, and S. Roundy, "An electromagnetic rotational energy harvester using sprung eccentric rotor, driven by pseudo-walking motion," Appl. Energy, vol. 217, pp. 66-74, 2018.

[20] L. Xie, C. G. Menet, H. Ching, and R. Du, "The Automatic Winding Device of a Mechanical Watch Movement and Its Application in Energy Harvesting," J. Mech. Des., vol. 131, no. 7, 2009.

[21] W. Ding, B. Song, Z. Mao, and K. Wang, "Experimental investigation on an ocean kinetic energy harvester for underwater gliders," 2015 IEEE Energy Convers. Congr. Expo. ECCE 2015, no. 20116102110009, pp. 1035-1038, 2015.

[22] Q. Guo et al., "Design and experiment of an electromagnetic ocean 
wave energy harvesting device," IEEE/ASME Int. Conf. Adv. Intel. Mechatronics, pp. 381-384, 2018.

[23] Z. Zhang, B. Chen, S. R. K. Nielsen, and J. Olsen, "Gyroscopic power take-off wave energy point absorber in irregular sea states," Ocean Eng., vol. 143, no. February, pp. 113-124, 2017.

[24] E. M. Y. Tzern T. Toh, A. Bansal, G. Hong, Paul D. Mitcheson, Andrew S. Holmes, "Energy harvesting from rotating structures," no. 50, pp. 4461-4462, 2007.

[25] J. Kokert, T. Beckedahl, and L. M. Reindl, "Medlay: A reconfigurable micro-power management to investigate self-powered systems," Sensors (Switzerland), vol. 18, no. 1, 2018.

[26] M. T. Penella and M. Gasulla, "Runtime extension of low-power wireless sensor nodes using hybrid-storage units," IEEE Trans.
Instrum. Meas., vol. 59, no. 4, pp. 857-865, 2010.

[27] F. Reverter and M. Gasulla, "Optimal Inductor Current in Boost DC/DC Converters Regulating the Input Voltage Applied to LowPower Photovoltaic Modules," IEEE Trans. Power Electron., vol. 32, no. 8, pp. 6188-6196, 2017.

[28] S. Heo, Y. S. Yang, J. Lee, S. Lee, and J. Kim, "Micro Energy Management for Energy Harvesting at Maximum Power Point," Integr. Circuits, vol. 13th, no. International Symposium, pp. 136$139,2011$.

[29] M. Carandell, D. Mihai, J. Río, K. Ganchev, and J. Peudennier, "Evaluation of Sigfox LPWAN technology for autonomous sensors in coastal applications," Instrum. Viewp. -, vol. 20, 2018. 